\title{
Strategic use of preference confirmation in group decision making: The role of competition and dissent
}

\author{
Claudia Toma ${ }^{*}$, Ingrid Gilles ${ }^{2}$ and Fabrizio Butera ${ }^{2}$ \\ 'Université Pierre Mendès France, Grenoble, France \\ ${ }^{2}$ Institut des Sciences Sociales, Université de Lausanne, Switzerland
}

\begin{abstract}
The present research investigates the moderating role of goal interdependence and dissent on individual preference confirmation in hidden-profile tasks. We propose that preference confirmation can be used strategically to deal with competition and dissent likely to arise in group decision making. In two studies, participants first received incomplete information about a car accident investigation, and then read a fictitious discussion with two other participants containing full information. The interaction with the fictitious participants was presented either as cooperative or competitive. We predicted and found preference confirmation to be higher in competition than cooperation, when initial preferences were dissenting (Studies I \& 2), but to be higher in cooperation than in competition, when initial preferences were consensual (Study 2). Also, the increased versus decreased preference confirmation in competition with, respectively, dissent and no dissent were found to be predicted by selfenhancement strategies (Study 2). These findings contribute to a better understanding of the boundary conditions of preference confirmation in hidden profiles and shed a new light on the role of motivated information processing in these tasks.
\end{abstract}

Many organizations rely on groups to make decisions, because they expect the confrontation of different viewpoints to increase the quality of decisions (Sessa, Jackson, \& Rapini, 1995). However, a great deal of research has shown that people are often reluctant to accept others' perspectives and prefer information consistent with their favoured or chosen alternative (e.g., Frey \& Schultz-Hardt, 2001; Schulz Hardt, Frey, Luthgens, \& Moscovici, 2000; Schulz-Hardt, Jochims, \& Frey, 2002). Imagine a young doctor making a diagnosis in a complex, risky case. Her superior requires her to meet with two fellow members of the medical team in order to discuss the case. They have different backgrounds, and they each possess unique additional information that leads them to

Claudia Toma is now at Université Catholique de Louvain at Louvain-la-Neuve, Belgium; Ingrid Gilles and Fabrizio Butera, Institut des Sciences Sociales, Université de Lausanne, Switzerland. Part of this work is based on Claudia Toma's doctoral dissertation under the supervision of Fabrizio Butera.

* Correspondence should be addressed to Fabrizio Butera, Université de Lausanne - ISS-SSP, Vidy, CH I0I5 - Lausanne, Switzerland (e-mail: fabrizio.butera@unil.ch). 
support different diagnoses. Although this confrontation is in the best interest of the patient and the team as a whole, competitive pressure, related to promotion or prestige, for instance, may exist within the team. Under these conditions, being open to others' divergent positions and information is neither easy nor constructive (e.g., Darnon, Butera, \& Harackiewicz, 2007; Darnon, Harackiewicz, Butera, Mugny, \& Quiamzade, 2007). Rather, people tend to process information in a way that is consistent with their initial preferences. This article aims to test the general hypothesis that confirmation of one's own preferences is motivated by competition and dissent in group decision making.

\section{Preference confirmation in hidden profiles}

In group decision-making research, hidden profiles portray tasks in which group members initially support suboptimal preferences, based on their information. They could detect a better solution by taking into account others' unshared information, but a number of studies have shown that most groups fail to solve hidden profiles (see for a review, Wittenbaum \& Stasser, 1996), either because group members do not discuss the unshared information (Stasser \& Titus, 1985, 1987) or because they use the discussion to exchange their preferences and, based on them, to negotiate the final decision (Gigone \& Hastie, 1993, 1997).

Studies have generally focused on group-level processes to account for group members' inability to discover hidden profiles (Winquist \& Larson, 1998). However, Greitemeyer and Schulz-Hardt (2003) have shown that, in the absence of any dysfunctional group-level process, individual group members still have difficulties in detecting the best solution because they exhibit an individual preference confirmation. These authors argue that members' initial preferences, derived from their own unshared information, lead them to evaluate subsequent information consistent with their initial preference more favourably than inconsistent information. In addition, Greitemeyer and Schulz-Hardt (2003) have shown that the preference for consistent information is the mediating mechanism of preference-consistent decisions. This work provides supplementary insights into hidden profiles by identifying an important individuallevel process that impedes group decision quality. However, individual- and group-level processes are often interrelated in hidden profiles and therefore the strength of individual preference confirmation could be moderated by group-level processes. In the present research, we propose that individual-level preference confirmation may serve grouplevel motives, such as dealing with dissenting partners in competitive decision-making situations.

\section{Cooperation and competition in hidden profiles}

Our first argument is that individual preference confirmation might be influenced by group members' goals. In Greitemeyer and Schulz-Hardt's research, participants were not instructed to pursue any specific social goal when confronted to others' information. However, most of hidden-profile studies implicitly assumed participants have cooperative goals when processing information, and thus underestimated the impact of competitive goals in this task (Wittenbaum, Hollingshead, \& Botero, 2004). Various competitive goals (desire to attain a high status, proving competence) are present in group decision making and they do affect processing activities and strategic behaviours (De Dreu \& Carnevale, 2003; Steinel \& De Dreu, 2004). Indeed, previous studies have shown that people may react defensively when their own preferences are questioned, especially if they are motivated by competition (De Dreu \& Van Knippenberg, 2005). 
Competition is associated with self-enhancement goals that individuals might strive to satisfy by using confirmatory strategies. Because competition diminishes the need to belong to the group, it reinforces concerns for superiority and differentiation (Hornsey \& Jetten, 2004). The confirmation of one's own initial preferences might be used as a strategy to attain this relational goal. Some studies suggested that under competition individuals confirm their own initial position (Butera \& Mugny, 1995, 2001), as this is helpful in preventing losing the competitive advantage (Leyens, Dardenne, Yzerbyt, Scaillet, \& Snyder, 1999). The self-enhancement motive activated by competition (Ross \& Wilson, 2003) may lead people to wrongly believe that they are right while the other is wrong, and therefore they may avoid disconfirming their initial preferences in competition. In line with this idea, Toma and Butera (2009) have recently shown that in hidden profiles, competition, compared to cooperation, increases the strategic use of confirmation at the group level.

\section{Cooperation and competition effects as a function of dissent}

Our second argument is that the above dynamics interact with the fact that individual preference confirmation is influenced by the diversity of individual members' preferences. A great deal of research suggests that dissent can have both reducing and enhancing effects on confirmation use.

On the one hand, research on group decision making show that dissent counteracts or eliminates the use of confirmation (e.g., Schulz-Hardt et al., 2000, 2002) and improves decision quality (Brodbeck, Kerschreiter, Mojzisch, Frey, \& Schulz-Hardt, 2002; Lam \& Schaubroeck, 2000; Schulz-Hardt, Brodbeck, Mojzisch, Kerschreiter, \& Frey, 2006). Moreover, research on minority influence reveals that dissent proceeding from consistent minorities stimulates divergent thinking and creativity (Legrenzi, Butera, Mugny, \& Pérez, 1991; Nemeth, 1986), leading to open-minded information processing (Tjosvold, Johnson, \& Lerner, 1981). On the other hand, research on social influence and hypothesis testing has shown that dissent can also enhance confirmation when coming from a majority (Butera, Mugny, Legrenzi \& Pérez, 1996; Nemeth \& Rogers, 1996) or a competent, high-status source (Butera, Caverni, \& Rossi, 2005).

By taking into account members' cooperative and competitive goals, it appears that both reducing and enhancing effects of dissent on preference confirmation should be predicted. According to the theory of cooperation and competition (Deutsch, 1949, 1973; see also Johnson \& Johnson, 1989, 2005), competition should increase preference confirmation, while cooperation should decrease this bias. In competition, individuals attempt to defend their own position by excluding the positions of others (Butera \& Mugny, 2001). Thus, dissent within competition induces defensive reactions and denial of alternative positions; recent research has shown that dissent (termed conflict in these articles) associated with competitive motives produces attempts to resist the other's position by maintaining one's own (Buchs, Pulfrey, Gabarrot, \& Butera, 2010; Darnon, Muller, Schrager, Pannuzzo, \& Butera, 2006). As suggested by Leyens et al., (1999), competition comes with a great deal of negative effects, and confirmation may be helpful in preventing losing the competitive advantage.

In cooperation, on the contrary, individuals trust each other and are encouraged to investigate alternative solutions and to assimilate divergent perspectives (Johnson \& Johnson, 2005). For instance, Buchs, Butera and Mugny (2004) showed that a truly cooperative interaction, as compared to a potentially competitive one, elicits more constructive effects such as better relationships, integration of the partner's perspective, and increased learning. Cooperation has also been shown to facilitate the processing of 
information in groups characterized by diversity (Homan et al., 2008). Thus, dissent within cooperation can help group members to overcome differences and to reduce the use of confirmation. In fact, the sense of complementarity it involves may even decrease individuals' tendencies to rely on preference confirmation. In sum, we expect that preference confirmation should appear most when disagreeing with competitors and least when disagreeing with cooperators.

\section{Overview and hypotheses}

We investigated individual preference confirmation in two studies by setting up a fictitious group discussion about a hidden-profile task, as in Greitmeyer and SchulzHardt (2003). Participants were first oriented towards a suboptimal initial preference. Then they received consistent and inconsistent information about their preference and were asked to evaluate this information and reach a final decision. Thus, in the present work, preference confirmation refers to two separate measures - preference for consistent information (higher ratings for consistent than for inconsistent information) and confirmatory decision (the final decision reproduces the initial preference). A pilot study was designed to assess whether the basic materials for the main experiment without manipulation of dissent and goal interdependence (cooperation, competition) replicated the preference confirmation effect observed by Greitmeyer and Schulz-Hardt (2003). The main studies directly manipulated cooperation and competition, as well as dissent.

In Studies 1 and 2, we expect that the preference for consistent information will occur to a greater extent in competition than in cooperation, when the dissent with others' preferences is present, but not when this dissent is absent (Hypotbesis 1). We also expect that, when asked to select the final decision, more participants in competition than in cooperation will adopt the confirmatory decision, when the dissent with others' preferences is present, but not when this dissent is absent (Hypothesis 2). We have argued that preference confirmation can be used as a strategic tool to deal with dissenting competitors; this implies that the two measures of preference confirmation, namely preference for consistent information and confirmatory decision, should be linked in a coherent behaviour. Therefore, on the basis of Hypotheses 1 and 2, we expect that the preference for consistent information should mediate the joint effect of goal interdependence and dissent on the confirmatory decision (Hypothesis 3, mediated moderation hypothesis). Finally, Study 2 directly tested the hypothesis that preference confirmation reflects strategic behaviour in competition. We therefore expect preference confirmation in competition to be related to self-enhancement strategies as a function of dissent (Hypothesis 4).

\section{STUDY I}

\section{Method}

\section{Participants and design}

Eighty undergraduate students from a large French university volunteered for this study. The sample included 41 women and 39 men $(M=25.67$ years, $S D=5.73$ ). A 2 (goal interdependence: cooperation, competition) $\times 2$ (dissent: present, absent) betweenparticipants factorial design was used. Five participants were excluded because they 
did not choose the intended initial preference. Twenty participants were randomly assigned to each experimental condition. Preliminary analyses revealed that gender did not influence main effects or interactions on our dependent variables; therefore, this variable was not included in the final analyses.

\section{Procedure and materials}

Participants had to find the guilty person in a car accident investigation. They worked individually, and then they were led to imagine that they would work in a team. The role-play story had participants pretend they worked as police inspectors with two other people in order to identify the party responsible for the car accident. Four people were potential suspects, but three of them could be exonerated (Mr. X, Mrs. Y, Mr. Z) and the fourth (Mr. X's son) incriminated based on a critical set of nine clues. The entire set of information contained 28 clues: 19 clues were shared, and the 9 critical clues were unshared. A hidden profile was created by distributing three different critical clues to the participant and the two other fictitious group members in a way that created an initial dissent: The naive participant was oriented toward Mr. X, while the fictitious participants were attributed Mrs. Y and Mr. Z as initial preferences. All participants were asked to express their initial preference (Mr. X), and then they were informed that they did not possess the entire set of information, and that for this reason, they would be provided with supplementary information given by the two other participants. Goal interdependence and dissent manipulations were introduced at this point. Participants were led to imagine that both their goal and that of the fictitious members was either to grant the group success (positive goal interdependence, i.e., cooperation) or to ensure the individual success (negative goal interdependence, i.e., competition) in the car accident investigation. It was also explained that a successful end of the investigation would provide them all (cooperation) or only one of them (competition) with a very promising promotion. With regard to dissent, participants were either told that others' initial preferences were, respectively, Mrs. Y and Mr. Z (dissent, participants are oriented towards an initial preference for $\mathrm{Mr}$. $\mathrm{X}$ ), or no information was provided (no dissent). Subsequently, participants received six items of information, three consistent and three inconsistent with their initial preference (Mr. X), supposedly coming from the two other people. An example of consistent information was that the person responsible for the accident is a man. An example of inconsistent information was that the person responsible for the accident is less than 30 years old (participants knew $\mathrm{Mr} . \mathrm{X}$ is 53 years old). The consistent and inconsistent information was presented in random order for each participant. Participants were asked to evaluate the items of information with regard to their importance in making an optimal decision. Finally, participants were asked to make a final decision based on all the information. All participants were asked to come up with the best decision. The participants were free to take as much time as they needed for each phase, but they were not allowed to go back to the previous phases. At the end of the session, participants were thanked and debriefed.

\section{Dependent measures}

Preference for consistent information

Participants evaluated to what extent the six received items of information were important in reaching the optimal decision, on a scale ranging from 1 (not at all important) to 9 (very important). As this information included three items consistent 
$(\alpha=.71)$ and three items inconsistent with participant initial preference $(\alpha=.79)$, a mean score for each type of information was computed. The preference for consistent information was computed by subtracting the ratings of the inconsistent information from the ratings of the consistent information, and refers to the extent to which participants evaluated information in a way that confirmed their initial preference. A positive score indicates that consistent information was considered more valuable than inconsistent information, and a negative score indicates that inconsistent information was considered more valuable than consistent information.

Confirmatory decision. We derived a dichotomous measure from the final decision reported by participants, namely the confirmatory decision, expressing whether participants maintained (coded 1$)$ or not (coded 0$)$ their initial preference $(\mathrm{Mr} . \mathrm{X})$.

\section{Pilot study}

A pilot study with 20 participants using the same material and the same procedure, but without the goal interdependence and dissent manipulations, was run independently, to assess whether the basic materials of the present experiment yielded similar results as compared with previous research. The results of this study show that participants evaluated consistent information $(M=5.85, S D=1.88)$ more favourably than inconsistent information $(M=4.90, S D=1.18), t(19)=2.18, p<.05$, which corresponds to a preference for consistent information. Moreover, most of these participants $(15 ; 75 \%)$ chose the confirmatory decision, $\chi^{2}(1, N=20)=5.00, p<.05$, thus replicating the preference confirmation effects found by Greitemeyer and Schulz-Hardt (2003).

\section{Results}

\section{Preference for consistent information}

To examine the preference for consistent information, we used a 2 (goal interdependence: cooperation, competition) $\times 2$ (dissent: present, absent) analysis of variance (ANOVA). This analysis revealed a main effect of goal interdependence, $F(1,76)=4.13$, $p<.05, \eta^{2}=.05$. More preference for consistent information occurred in competition $(M=0.37, S D=2.19)$ than in cooperation $(M=-0.50, S D=1.81)$. No main effect of dissent was found, $F(1,76)=1.39, p=.24, \eta^{2}=.02$. More importantly, the predicted two-way interaction between goal interdependence and dissent was significant, $F(1,76)=7.87, p<.01, \eta^{2}=.09$. Follow-up analyses showed that in the dissent condition, more preference for consistent information occurred in competition $(M=$ $1.23, S D=2.56)$, than in cooperation, $(M=-0.85, S D=2.06), F(1,76)=8.01, p<.01$, $\eta^{2}=.10$. When dissent was absent, no difference between competition $(M=-0.48$, $S D=1.33)$ and cooperation $(M=-0.15, S D=1.49)$ was found, $F<1$. These results, ${ }^{1}$ which support hypothesis 1, are illustrated in Figure 1.

\section{Confirmatory decision}

Overall, 31 of 80 participants (38.75\%) chose this decision. Logistic regression analyses revealed a main effect of goal interdependence, $B=-.61, S E=.25$, Wald $\chi^{2}(1, N=80)=$

\footnotetext{
I In Study I preference for consistent information was significantly different from 0 , only in competition with dissent, $t=2.15$, $p<.05$, all other $p s>.10$. In Study 2 preference for consistent information was marginally different from 0 in competition with dissent and in cooperation with no dissent, $t=1.93, p=.06$, while preference for inconsistent information was significantly different from 0 in cooperation with dissent, $t=-3.77, p<.001$, all other $p s>.10$.
} 


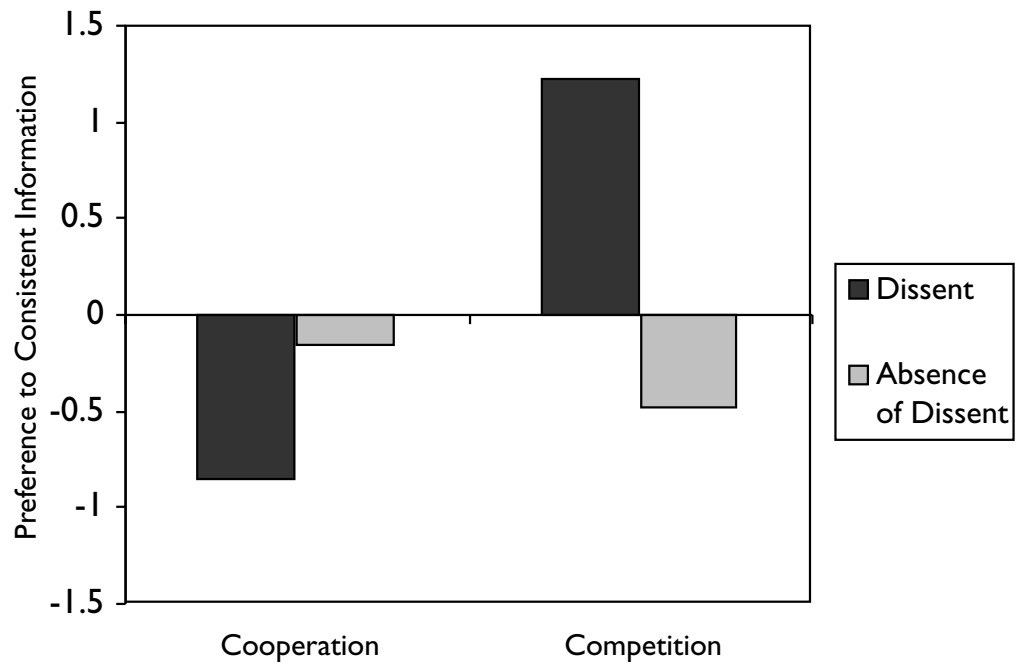

Figure I. Preference for consistent information as a function of goal interdependence and dissent (Study I).

$6.48, p<.05:$ More participants chose the confirmatory decision in competition (21; $52.5 \%)$ than in cooperation $(10 ; 25 \%)$. No main effect of dissent was found, $B=-.27$, $S E=.23$, Wald $\chi^{2}(1, N=80)=1.30, p=.26$. Furthermore, the predicted interaction between goal interdependence and dissent was significant, $B=.50, S E=.25$, Wald $\chi^{2}(1, N=80)=4.12, p<.05$ : In the dissent condition, significantly more participants chose the confirmatory decision in competition (14) than in cooperation (4), $B=.50$, $S E=.13$, Wald $\chi^{2}(1, N=80)=4.91, p<.05$, while when dissent was absent the effect of goal interdependence was not significant, $B=.05, S E=.16$, Wald $\chi^{2}<1$ (six participants in cooperation compared to seven participants in competition). These results ${ }^{2}$ support hypothesis 2 . The proportions of confirmatory decisions corresponding to each condition are presented in Table 1.

\section{Mediated moderation analysis}

We tested whether the goal interdependence by dissent interaction effect on the confirmatory decision was due to a preference for consistent information, which corresponds to hypothesis 3. The tested model is depicted in Figure 2. We followed the procedure set forth by Muller, Judd, and Yzerbyt (2005). Goal interdependence and dissent were contrast coded (cooperation -1 , competition +1 ; no dissent -1 ,

\footnotetext{
${ }^{2}$ We also analyzed the proportion of correct decisions expressing whether participants identified (coded I) or not (coded 0 ) the best decision corresponding to the discovery of the hidden profile (Mr. X's son). In Study I, these analyses revealed a main effect of goal interdependence, $\Delta \chi^{2}(I, N=80)=5 . I I, p<.05$. In cooperation more participants chose the correct solution $(24 ; 60 \%)$ than in competition (13;32.5\%). A main effect of dissent was also found, $\Delta \chi^{2}$ $(I, N=80)=5 . I I, p<.05:$ In the dissent condition fewer participants chose the correct solution (I3; 32.5\%) than in the no dissent condition $(24 ; 60 \%)$. In Study 2 analyses on the proportion of correct decisions revealed an interaction between goal interdependence and dissent $\Delta \chi^{2}(I, N=I 20)=9.0 I, p<.0 I$. In the dissent condition, more participants chose the correct solution in cooperation (9; $45 \%)$ than in competition $(2 ; 10 \%)$ or in control condition $(3 ; 15 \%), \Delta \chi^{2}(I, N=I 20)=$ $8.01, p<.01$. In the no dissent condition, more participants chose the correct solution in competition $(10 ; 50 \%)$ than in cooperation (4; $20 \%$ ) or in control condition (6; 30\%), but this effect was not significant $\Delta \chi^{2}(I, N=I 20)=4.20, p=. I 2$.
} 
Table I. Proportions of confirmatory decisions in Studies I and 2

\begin{tabular}{lccccccc}
\hline & \multicolumn{3}{c}{ Dissent } & & \multicolumn{3}{c}{ No dissent } \\
\cline { 2 - 3 } & Cooperation & Control & Competition & & Cooperation & Control & Competition \\
\hline Study 1 & 0.20 & & 0.70 & & 0.30 & & 0.35 \\
Study 2 & 0.30 & 0.50 & 0.75 & & 0.60 & 0.55 & 0.35 \\
\hline
\end{tabular}

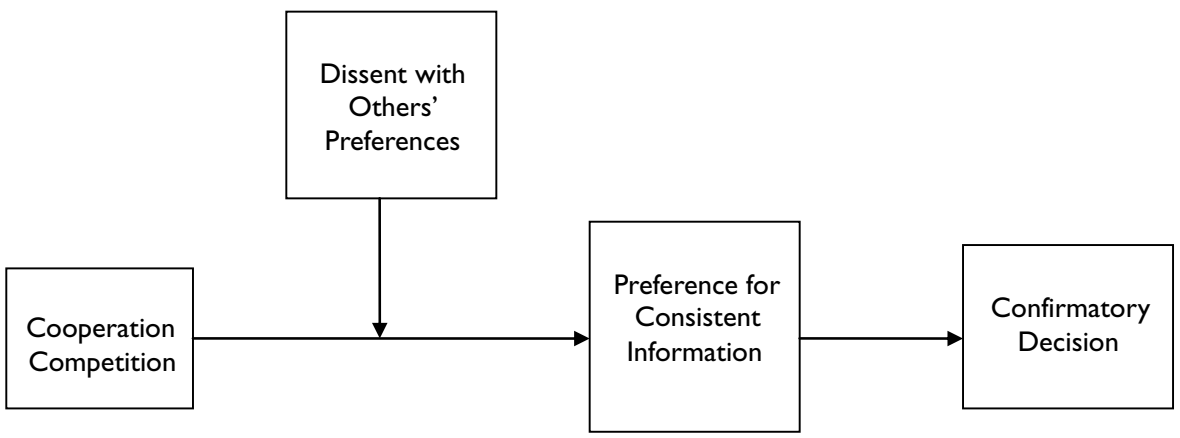

Figure 2. The moderated mediation model used to predict the confirmatory decision.

dissent +1 ), and preference for consistent information was centred at its mean. An overall moderation of goal interdependence and dissent was first tested on the dependent variable (confirmatory decision) and on the mediating variable (preference for consistent information). Then, we tested whether controlling for preference for consistent information reduced the overall moderation. Two multiple logistic regressions and one linear multiple regression were used for the three equations. In the first equation, the overall moderation was found on the confirmatory decision, $B=2.00, S E=1.00$, Wald $\chi^{2}(1, N=80)=3.98, p<.05$. In the second equation, the overall moderation was found on the preference for consistent information, $B=-3.01, S E=.92, t(79)=$ $-3.29, p<.001$. In the third equation, when controlling for preference for consistent information, the overall moderation was no longer reliable, $B=1.10, S E=1.17$, Wald $\chi^{2}(1, N=80)=0.89, p=.35$, while the preference for consistent information still predicted the confirmatory decision, $B=-.53, S E=.17$, Wald $\chi^{2}(1, N=80)=9.73$, $p<.01$. Moreover, the residual of the moderation of goal interdependence by dissent was reduced from $B=2.00$ to $B=1.10$, one-tailed $Z_{\text {Sobel }}=-1.68, p<.05$. Table 2 presents the regression models that estimate equations 1 through 3 with these variables.

\section{Discussion}

The pilot study, where neither goals nor dissent were manipulated, replicates the preference confirmation effect thereby supporting the relevance of the present materials for the study of individual-level preference confirmation. Study 1 showed that participants exhibited more preference confirmation and chose more confirmatory decisions in competition than in cooperation, only when they were informed about others' dissenting preferences (hypotheses 1 and 2). The mediated moderation analysis confirmed that the preference for consistent information is fully responsible for the confirmatory decisions (hypothesis 3). These results were in line with our first three hypotheses. 
Table 2. Least square regression results for the mediated moderation model in Study I

\begin{tabular}{|c|c|c|c|c|c|c|}
\hline \multirow[b]{2}{*}{ Predictors } & \multicolumn{2}{|c|}{$\begin{array}{c}\text { Equation I } \\
\text { (criterion CD) }\end{array}$} & \multicolumn{2}{|c|}{$\begin{array}{c}\text { Equation } 2 \\
\text { (criterion PREFCOINF) }\end{array}$} & \multicolumn{2}{|c|}{$\begin{array}{c}\text { Equation } 3 \\
\text { (criterion CD) }\end{array}$} \\
\hline & B & Wald & B & $t$ & B & Wald \\
\hline IV : GOAL & 1.231 & $6.0 I^{*}$ & -0.575 & -1.25 & 1.088 & 3.46 \\
\hline MO: DISSENT & 0.464 & 0.85 & -0.808 & -1.76 & 0.109 & 0.03 \\
\hline IV $\times$ MO & 2.005 & $3.98^{*}$ & -3.017 & $-3.29 * * *$ & 1.103 & 0.89 \\
\hline ME: PREFCOINF & & & & & -0.529 & $9.73^{* *}$ \\
\hline $\mathrm{ME} \times \mathrm{MO}$ & & & & & -0.391 & 1.32 \\
\hline
\end{tabular}

Note. $\mathrm{CD}=$ confirmatory decision, PREFCOINF = preference for consistent information, IV = independent variable, $\mathrm{MO}=$ moderator variable, $\mathrm{ME}=$ mediator variable. ${ }^{*} p<.05 ;{ }^{* *} p<.0 \mathrm{I}$; ${ }^{* * *} p<.001$.

\section{STUDY 2}

We conducted a second study in order to further investigate the role of goal interdependence and dissent. The first aim of this study was to replicate Study 1 using a different manipulation of dissent. In Study 1, the no dissent condition was operationalized by not informing participants about other members' preferences. Therefore, it was not clear whether the results were the consequence of the dissent per se or the consequence of receiving information about others' preferences. A recent study by Mojzisch and SchulzHardt (2010) showed that simply knowing others' preferences has a strong negative impact on information processing. Therefore, in this study, all participants were informed about other members' preferences but they either learned that these preferences differed from their own or that others' preferences were the same as their own.

The second aim was to clarify the role of dissent with regard to cooperation and competition. In Study 1, a difference in preference confirmation was found between cooperation and competition in the dissent condition, but it is not clear yet whether the dissent increased the preference confirmation in competition or whether it decreased it in cooperation. Therefore, in Study 2 a baseline condition without goal instructions was added to the cooperation and competition conditions.

The third aim of Study 2 was to provide more compelling evidence that preference confirmation reflects strategic behaviour in competition. As suggested in the introduction, competition may motivate people to use self-enhancement strategies in order to avoid disconfirming their preferences when facing the dissent with their opponents. It is widely known that self-enhancement reflects strivings to raise one's positive self-view and superiority (Alicke \& Sedikides, 2009). Because competition generally strengthens these concerns (Hornsey \& Jetten, 2004), competition may motivate people to use preference confirmation as a self-enhancement strategy. Therefore, in this study we tested whether in competition self-enhancement predicted preference confirmation as a function of dissent (Hypothesis 4).

\section{Method}

\section{Participants and design}

One hundred twenty-two students from a large Belgian university volunteered for this study. The sample included 88 women and 34 men $(M=22.79$ years, $S D=2.58)$. 
A 3 (goal interdependence: cooperation, competition, control) $\times 2$ (dissent: yes, no) between-participants factorial design was used. Two participants were excluded because they did not choose the intended initial preference. Twenty participants were randomly assigned to each experimental condition.

\section{Procedure and materials}

The procedure and materials were very similar to those of Study 1 . We used the same decision task. Participants were again oriented towards Mr. $\mathrm{X}$ as initial preference, while fictitious group members were allegedly suggesting Mrs. Y and Mr. Z in the dissent condition and the same Mr. X preference in the no dissent condition. Cooperation and competition were induced using the same instructions as in Study 1. However, in order to clearly understand the relative role of dissent in cooperation and competition, we included a control condition in which participants were confronted with other members' preferences without any specific goal instruction. Subsequently, participants responded to the self-enhancement measure (see below) and then they evaluated the supplementary information items (half consistent and half inconsistent with their preference) provided by the two other members, by indicating their importance in making an optimal decision. Finally, participants were asked to make a final decision based on all the information and responded to manipulation checks questions. At the end of the session, participants were thanked and debriefed.

\section{Dependent measures}

Preference for consistent information

Participants evaluated to what extent the six items of consistent and inconsistent information were important in reaching the optimal decision, on a scale ranging from 1 (not at all important) to 9 (very important). Again, the preference for consistent information was computed by subtracting the ratings of inconsistent information $(\alpha=.71)$ from the ratings of consistent information $(\alpha=.80)$.

\section{Confirmatory decision}

This dichotomous measure expressed whether participants maintained (coded 1) or not (coded 0 ) their initial preference $(\mathrm{Mr} . \mathrm{X})$ when asked to make a final decision.

\section{Self-enhancement}

This measure refers to participants' motivation to affirm their superiority and their positive self-view during the decision task. Participants responded to five questions ('I would like my decision to be better than those of others', 'I would do anything to prove that I'm superior to others', 'I wouldn't like others to outperform me', 'I couldn't stand to be perceived as incompetent', 'I would stand up for my decision') on a scale ranging from $(1=$ not at all $)$ to $9(=y e s$, definitely $)$. These items were combined into a single score $(\alpha=.74)$.

\section{Manipulation checks}

Five questions concerned with perception of competition and perception of dissent were answered on a 9-point scale ranging from 1 (not at all) to 9 (yes, definitely). 
Three questions referring to perception of competition ('I had reasons to mistrust the others', 'In a real interaction, the atmosphere would have been tense', 'My goal was to help others to find the correct solution - reversed-score') were combined into a single mean score $(\alpha=.62)$. Two questions referring to perception of dissent ('Others' preferences were different / the same as mine'.) were combined into a single mean score $(r=.85)$.

\section{Results}

\section{Manipulation checks}

Perception of competition and perception of dissent were both analyzed with a 3 (goal interdependence: cooperation, control, competition) $\times 2$ (dissent: yes, no) ANOVA. Perception of competition was higher in competition $(M=5.16, S D=1.49)$, than in the control condition $(M=3.45, S D=1.31)$ and cooperation $(M=2.98, S D=1.48)$, $F(2,114)=28.12, p<.001, \eta_{\mathrm{p}}{ }^{2}=.33$. The main effect of dissent and the interaction were not significant (dissent, $F<1$; interaction, $F(2,114)=2.46, p=.09$ ).

Perception of dissent was higher in the dissent condition $(M=7.82, S D=1.56)$ than in the no dissent condition $(M=2.24, S D=2.13), F(1,114)=271.02, p<.001, \eta_{\mathrm{p}}{ }^{2}=.70$. The main effect of goal interdependence and the interaction were not significant (goal interdependence, $F<1$; interaction, $F(2,114)=2.55, p=.08)$. Despite this marginal interaction, dissent was perceived as more important in the dissent condition than in the no dissent condition in all goal conditions (competition: $M=7.50, S D=1.61$ vs. $M=3.00, S D=2.86$; control: $M=7.90, S D=1.39$ vs. $M=1.82, S D=1.61$; cooperation: $M=8.07, S D=1.71$ vs. $M=1.90, S D=1.55$; for the three $t$ tests $p<.001)$.

\section{Overview of main analyses}

To test our main hypotheses we used regression analyses (linear regressions when the dependent variable was preference for consistent information and logistic regression when the dependent variable was confirmatory decision). Goal interdependence (competition, control and cooperation) was defined by two orthogonal contrasts: $\mathrm{C} 1$, the linear contrast $(-1,0,+1)$ corresponding to our hypotheses and $\mathrm{C} 2$, the quadratic contrast $(-1,+2,-1)$ corresponding to the residual variance. The proper use of contrast analysis requires $\mathrm{C} 1$ to be significant and C2 to be non-significant (Abelson \& Prentice, 1997). Dissent (present, absent) was defined by a C3, difference contrast $(+1,-1)$. The two goal interdependence by dissent interactions were computed by multiplying the linear, and respectively the quadratic contrast corresponding to goal interdependence, with the difference contrast corresponding to dissent. In sum, five predictors were used for each regression model.

\section{Preference for consistent information}

When preference for consistent information was regressed on the five predictors, this analysis revealed no main effect of goal interdependence (neither the linear, $B=-.23$, $S E=.25, t<1$, nor the quadratic contrast were significant, $B=.15, S E=.14, t=$ $1.03, p=.31$ ) and no main effect of dissent, $B=-.35, S E=.21, t=-1.69, p=.09$. The predicted two-way interaction between the linear contrast corresponding to goal interdependence and dissent was significant, $B=-1.01, S E=.25, t=-3.98, p<.001$, 
while the two-way interaction between the quadratic contrast corresponding to goal interdependence and dissent was not significant, $B=-.12, S E=.15, t<1$.

We further conducted simple effect analyses in order to better understand the role of goal interdependence in the dissent and no dissent conditions. When dissent was present we expected more preference for consistent information in competition than in cooperation, as in Study 1, but our theoretical hypothesis - that preference confirmation should appear most when disagreeing with competitors and least when disagreeing with cooperators - also implied that preference confirmation in the control condition should be in between that of cooperation and competition. This analysis revealed that the linear contrast $\mathrm{C} 1$ was significant, $B=-1.24, S E=.36, t=-3.45, p<.001$, while the quadratic contrast $\mathrm{C} 2$ was not, $B=.03, S E=.21, t<1$. The preference for consistent information was, as expected, higher in competition $(M=0.87, S D=2.59)$, than in the control condition $(M=-0.28, S D=1.62)$, which in turn was higher than in cooperation $(M=-1.62, S D=1.91)$. In the no dissent condition, the linear contrast $\mathrm{C} 1$ was also significant, $B=.78, S E=.36, t=2.18, p<.05$, while the quadratic contrast $\mathrm{C} 2$ was not, $B=.27, S E=.21, t=1.31, p=.19$. The preference for consistent information was this time lower in competition $(M=-0.70, S D=2.68)$, than in the control condition $(M=0.90, S D=2.60)$, and cooperation $(M=0.87, S D=2.00)$, but post hoc analyses revealed that the control condition did not differ from the cooperation condition, $p>.05$. These results are illustrated in Figure 3 .

\section{Confirmatory decision}

Overall, 61 of 120 participants (50.83\%) chose this decision. When confirmatory decision was regressed on the five predictors, logistic regression analyses revealed no main effect of goal interdependence (neither the linear nor the quadratic contrasts were significant) or dissent (the three Wald $\chi^{2}<1$ ). However, the predicted interaction between the linear contrast corresponding to goal interdependence and dissent was significant, $B=-.74, S E=.24$, Wald $\chi^{2}(1, N=120)=9.46, p<.01$, while the interaction between the quadratic contrast corresponding to goal interdependence and dissent was not significant, Wald $\chi^{2}<1$. We further conducted simple effect analyses in order to better understand the

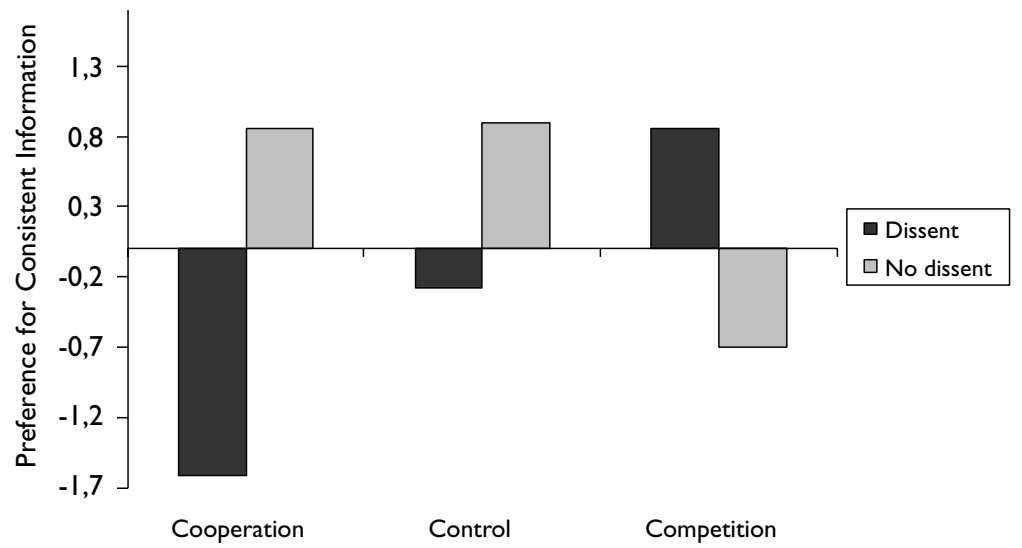

Figure 3. Preference for consistent information as a function of goal interdependence and dissent (Study 2). 
role of goal interdependence in the dissent and no dissent conditions. When dissent was present, as predicted by hypothesis 2 , more participants chose the confirmatory decision in competition (15) than in the control condition (10), which in turn is more than in cooperation (6). This corresponds to a significant linear contrast $\mathrm{C} 1(-1,0,+1), B=-.37$, $S E=.12$, Wald $\chi^{2}(2, N=120)=8.14, p<.05$. In the no dissent condition, the linear contrast was also significant, $B=.40, S E=.13$, Wald $\chi^{2}(2, N=120)=8.55$, $p<.01$. This time, less participants chose the confirmatory decision in competition (7) than in the control condition (11) and cooperation (12). The proportions of confirmatory decisions corresponding to each condition are presented in Table 1.

\section{Mediated moderation analysis}

We tested whether the goal interdependence by dissent interaction effect on the confirmatory decision was due to a preference for consistent information, which corresponds to hypothesis 3 . The same model as above was used, where goal interdependence was coded using two orthogonal contrasts: a linear contrast $\mathrm{C} 1(-1,0,+1)$ and a quadratic contrast $\mathrm{C} 2(-1,+2,-1)$, and dissent was contrast coded $(-1,+1)$; preference for consistent information was centred at its mean. The interaction between the linear contrast corresponding to goal interdependence and dissent was found on the confirmatory decision, $B=-.74, S E=.24$, Wald $\chi^{2}(1, N=120)=9.46, p<.01$. The same moderation was also found on the preference for consistent information, $B=$ $-1.01, S E=.25, t(119)=-3.98, p<.001$. When controlling for preference for consistent information, the overall moderation lost its significance, $B=-.45, S E=.27$, Wald $\chi^{2}(1, N=120)=2.88, p=.09$, while the preference for consistent information still significantly predicted the confirmatory decision, $B=.40, S E=.11$, Wald $\chi^{2}(1, N=120)=$ $13.41, p<.001$. Moreover, the residual of the moderation of goal interdependence by dissent was reduced from $B=-.74$ to $B=-.45, \mathrm{Z}_{\text {Sobel }}=-2.70, p<.01$. Table 3 presents the regression models that estimate equations 1 through 3 with these variables.

Table 3. Least square regression results for the mediated moderation model in Study 2

\begin{tabular}{|c|c|c|c|c|c|c|}
\hline \multirow[t]{2}{*}{ Predictors } & \multicolumn{2}{|c|}{$\begin{array}{c}\text { Equation I } \\
\text { (criterion CD) }\end{array}$} & \multicolumn{2}{|c|}{$\begin{array}{c}\text { Equation } 2 \\
\text { (criterion PREFCOINF) }\end{array}$} & \multicolumn{2}{|c|}{$\begin{array}{c}\text { Equation } 3 \\
\text { (criterion } C D \text { ) }\end{array}$} \\
\hline & B & Wald & B & $t$ & $B$ & Wald \\
\hline IV $(\mathrm{CI}):$ GOAL & -0.230 & 0.91 & -0.229 & -0.90 & -0.151 & 0.32 \\
\hline IV (C2): GOAL & 0.030 & 0.05 & 0.151 & 1.03 & -0.027 & 0.03 \\
\hline MO: DISSENT & 0.044 & 0.05 & -0.350 & -1.68 & 0.217 & 1.01 \\
\hline $\mathrm{IV}(\mathrm{Cl}) \times \mathrm{MO}$ & -0.743 & $9.45^{* *}$ & -1.013 & $-3.98^{* * *}$ & -0.454 & 2.88 \\
\hline IV $(\mathrm{C} 2) \times \mathrm{MO}$ & -0.072 & 0.29 & -0.121 & -0.82 & -0.061 & 0.18 \\
\hline ME: PREFCOINF & & & & & 0.405 & $|3.4|^{* * *}$ \\
\hline$M E \times M O$ & & & & & 0.036 & 0.10 \\
\hline
\end{tabular}

Note. $\mathrm{CD}=$ confirmatory decision, PREFCOINF = preference for consistent information, IV = independent variable, $\mathrm{MO}=$ moderator variable, $\mathrm{ME}=$ mediator variable. ${ }^{*} p<.05 ;{ }^{* *} p<.0 \mathrm{I}$; ${ }^{* * *} p<.001$. 


\section{Self-enhancement and preference for consistent information}

In hypothesis 4, we expected that competition would elicit self-enhancement strategies, such as using preference confirmation as a function of dissent. The specific prediction was therefore that, since - as argued in the introduction - self-enhancement is a typical strategy in competitive settings, ${ }^{3}$ it should positively predict preference confirmation in case of dissent. The regression model used to predict the preference for consistent information included as predictors: goal interdependence (decomposed by the two orthogonal contrasts C1, C2), dissent, self-enhancement, and all the two-way and the three-way interactions between these variables. ${ }^{4}$ The analysis revealed a three-way interaction between the linear contrast corresponding to goal interdependence, dissent, and self-enhancement, $B=-0.29, S E=.11, t=-2.60, p<.05$. Follow-up analyses revealed that the predicted two-way interaction between self-enhancement and dissent in competition was significant, $B=1.13, S E=.37, t=3.07, p<.01$. Simple slopes analysis showed that in the dissent condition, as predicted, self-enhancement positively predicted the preference for consistent information, $B=1.15, S E=.52, t=2.21$, $p<.05$, while in the no dissent condition, self-enhancement negatively predicted the preference for consistent information, $B=-1.12, S E=.52, t=-2.14, p<.05$.

\section{Discussion}

Results of Study 2 replicated those of Study 1. Indeed, in the dissent condition preference confirmation was higher in competition than in cooperation, which was not the case in the no dissent condition (hypothesis 1). Actually, in the no dissent condition preference confirmation was higher in cooperation than in competition; it is possible that in Study 2 - where, unlike Study 1, the no dissent condition implied that participants had exactly the same preferences as the alleged partners - cooperation created a sort of groupthink effect (Janis, 1972), whereby participants were particularly focused on consensus. Moreover, an intriguing finding was the presence of preference disconfirmation in competition with no dissent. Although not predicted by our hypothesis, this behaviour was also related to self-enhancement. This suggests that all participants in competition were motivated by self-enhancement, but they used confirmation when others supported different preferences (dissent) and used disconfirmation when others supported the same preference (no dissent), likely in an attempt to reinstate differences, a phenomenon known as 'dissimilation' (Lemaine \& Personnaz, 1981). Finally, under dissent, participants in the

\footnotetext{
${ }^{3}$ Indeed, it appeared that self-enhancement is typical of competition. A 2 (goal interdependence: cooperation, control, competition, control) $X 2$ (dissent: yes, no) ANOVA revealed a main effect of goal interdependence, $F(2, I I 4)=24.88, p<$ $.001, \eta_{\mathrm{p}}{ }^{2}=.30$. Self-enhancement was higher in competition $(M=6.41, S D=1.06)$ than in the control condition $(M=$ $4.55, S D=1.52)$, and cooperation $(M=4.72, S D=1.15)$. The specific contrast $C 4(+2,-I,-I)$ opposing the competition to the other two conditions was significant, $B=0.59, S E=.08, t=7.03, p<.00 I$, while the contrast $C 5(0,+I,-I)$ was not significant, $B=-.08, S E=.14, t<I$. Neither the main effect of dissent, nor the interaction were significant, $F(I, I \mid 4)=$ 2.33, $p=.13$ and $F<I$. Moreover, the means for self-enhancement in the cooperation and control conditions were not significantly different from the mid-point of the scale, respectively $t=I .23, p=.22$ and $t<I$, while they were significantly different in competition, $t=38.18, p<.001$, which suggests that the self-enhancement appears only competition.
}

${ }^{4} \mathrm{Goal}$ interdependence and self-enhancement were correlated $r=-.45, p<.00 \mathrm{I}$, but colinearity statistics confirmed the absence of multicolinearity. Tolerance coefficients were.78 and.70 and the VIF coefficients were 1.29 and I.43 for goal interdependence and self-enhancement. 
control condition exhibited an intermediate level of preference confirmation, lower than in competition, but higher than in cooperation, suggesting that dissent can have both reducing and enhancing effects on preference confirmation as a function of goal interdependence.

With regard to decision quality, more participants chose the confirmatory decision in competition than in cooperation in the dissent condition, which was not the case in the no dissent condition (hypothesis 2). Again, and consistent with the above analysis, in the no dissent condition more participants chose the confirmatory decision in cooperation than in competition. Notwithstanding the complexity of the experimental design, we replicated the mediated moderation effect found in Study 1, showing that the preference for consistent information mediated the predicted interaction effect on the confirmatory decision (hypothesis 3). Finally, consistent with the specific hypothesis of Study 2 (hypothesis 4), participants in competition, who exhibited a high level of self-enhancement (superior to control condition and cooperation), displayed a positive relationship between self-enhancement and the preference for consistent information in the dissent condition; self-enhancement in competition was also correlated with the preference for consistent information in the dissent condition but this time in a negative way. In other words, all participants in competition were motivated by self-enhancement, but this motivation positively predicted preference confirmation in the dissent condition, and negatively in the no dissent condition, underlining that preference confirmation may very well be a strategic way to cope with competition.

\section{GENERAL DISCUSSION}

\section{Preference confirmation, a motivated process}

Our general contention is that preference confirmation partly reflects a motivated process that serves hidden profile members' goals. Greitemeyer and Schulz-Hardt (2003) have shown that preference confirmation could be responsible for members' inability to reach optimal decisions. We proposed that individual members may exhibit preference confirmation, especially in competition, compared to cooperation, when they face the dissent of others' preferences. This hypothesis was fully supported by our results. In the pilot study, where neither goals nor dissent were manipulated, we replicated the overall preference confirmation effect - both on preference for consistent information and confirmatory decision - thereby supporting the relevance of the present materials for the study of individual-level preference confirmation. In the two main studies, however, where both goals and dissent were manipulated, we found that participants did not exhibit an overall preference confirmation, but rather used confirmation as a function of goals and dissent. The two-way interaction predicted by hypothesis 1 , and found in both studies, revealed that, when informed about others' dissenting preferences, participants in competition exhibited a preference for consistent information more than participants in cooperation, which was not the case when participants were not informed about dissent (Study 1) or when participants were informed that there was no dissent (Study 2). Interestingly, Study 2 has shown that cooperation can also increase preference confirmation when group members share consensual preferences. This is consistent with studies showing that confirmation bias is aggravated in groups with homogenous preferences (Frey, 1986; Jonas, Schulz-Hardt, Frey, \& Thelen, 2001). Our research contributes to this line of research by pointing out the role of cooperation in inducing this effect. 
The result on the final decision nicely complemented the picture, as more participants kept their initial preference in competition than in cooperation in the dissent condition, which was not the case without dissent, as predicted by hypothesis 2 . Patterning the results for preference confirmation, in Study 2, the no dissent condition revealed that more participants kept their initial preference in cooperation than in competition. Finally, the mediated moderation analysis fully demonstrates that the mechanism underlying the choice of confirmatory decision is the more favourable evaluation of information consistent with participants' initial preference. In other words, when participants attributed higher value to consistent than to inconsistent information, namely in competition with dissent, this resulted in being more prone to stick to the initial preference. Greitemeyer and Schulz-Hardt's (2003) had also found a mediational effect of preference for consistent information. However, because of the moderating effect of goals and dissent on information evaluation, we are suggesting here that participants may strategically distort their evaluation of available information so that they can maintain their preferences at the decision stage. Greitemeyer and SchultzHardt (2003) suggested that preference confirmation is due to insufficient amounts of cognitive resources allocated to consistent and inconsistent information. The present research adds that, notwithstanding the presence of a cognitive deficit effect, a strategic distortion of information evaluation might occur as a function of the goals implied by the decision-making setting. This is in line with a motivated information-processing approach in decision making, proposing that individual members deliberately select what information to mention and how to mention it to in order to satisfy relevant goals (De Dreu, Nijstad, \& van Knippenberg, 2008; Toma \& Butera, 2009; Wittenbaum et al., 2004).

\section{Strategic information processing and underlying motivations}

We propose in this research that preference confirmation in competition is associated with self-enhancement strategies. By maintaining their initial preferences when confronted with the dissenting preferences coming from others, participants strived to affirm their superiority and to keep the competitive advantage. However, when confronted with consensus in initial preferences, the same self-enhancement strategy predicted participants' propensity to use disconfirmation and to change their preferences. This provides supplementary evidence that people behave strategically in competition because they used confirmation only when other's preferences were different from their own. This is consistent with work on achievement goals, demonstrating that endorsement of performance-approach goals (competitive goals) is linked with the desire to regulate this interaction with a partner by showing that one is right and the other is wrong (Darnon et al., 2006; see also Buchs et al., 2010). This is also consistent with work on negotiation, emphasizing that existing biases in information processing should be reconsidered in order to identify social stakes and motivational concerns that might guide individual group members to a strategic use of information (Steinel \& De Dreu, 2004). Previous research has shown that information processing and strategic decisions are influenced by goals; cooperative negotiators reach agreements of higher joint gain than competitive negotiators (De Dreu, Weingart, \& Kwon, 2000), and cooperators exchange more accurate information than competitors, who strategically misrepresent their preferences in social decision making (Murnighan, Babcock, Thompson, \& Pillutla, 1999; Steinel \& De Dreu, 2004). 
Recent studies on conformity also show the existence of intra-group strategic behaviour associated with cooperation (Jetten, Hornsey, \& Adarves-Yorno, 2006). This research suggests that conformity is functional and group members with low status might strategically use this behaviour to appear as cooperative within the group. In Study 2 participants in cooperation with no dissent, tended to maintain their preference, probably in an attempt to conform to the group. Future studies should explore the exact underlying motivation of strategic preference confirmation in cooperation. Therefore, because the strategic use of preference confirmation was never addressed by previous research on hidden profiles, we believe that the present results are an important contribution in this domain.

\section{Individual- and group-level processes in hidden profiles}

Our research implies that although individual preference confirmation can explain suboptimal decisions in hidden profiles, this individual process is moderated by grouplevel processes such as members' goals and the diversity in initial preferences. Previous research overlooked that in hidden profiles individual members may be driven by a mixture of cooperative and competitive goals that can impact the willingness to confirm initial preferences. Research conducted at the group level has already shown that, independently of dissent, competition induces more use of confirmatory strategies than cooperation (Toma \& Butera, 2009). The current study replicates this effect and extends this work to the individual level.

We have pointed out that group members' inability to discover hidden profiles has been attributed for a long time to group-level processes (Winquist \& Larson, 1998). Later, Greitemeyer and Schulz-Hardt (2003) have shown that, in the absence of any dysfunctional group-level process, individual group members still have difficulties in detecting the best solution because they exhibit an individual-level preference confirmation. Our research adds that the above two views need to be considered as complementary: The results reported in the present study show that the individual-level preference confirmation effect is moderated by group-level processes. This integration suggests that preference confirmation is indeed an important feature of group decision making, that should be taken into account in professional and educational settings; it is not, however, an inevitable feature. This research shows that it can be reduced by providing a cooperative context for decision making, in which the diversity in positions and solutions can be viewed as a contribution and not a hindrance.

\section{Acknowledgements}

This work was supported by an 'Ecole et Sciences Cognitives' fund granted by the French Ministry for Research, and by the Swiss National Science Foundation. We wish to thank Caroline Pulfrey and Olivier Corneille for helpful comments on earlier versions of the manuscript.

\section{References}

Abelson, R. P., \& Prentice, D. A. (1997). Contrast tests of interaction hypotheses. Psychological Methods, 2, 315-328. doi:10.1037/1082-989X.2.4.315 
Alicke, M. D., \& Sedikides, C. (2009). Self-enhancement and self-protection: What they are and what they do. European Review of Social Psychology, 20, 1-48. doi:10.1080/10463280802613866

Brodbeck, F., Kerschreiter, R., Mojzisch, A., Frey, D., \& Schulz-Hardt, S. (2002). The dis-semination of critical, unshared information in decision-making groups: The effects of pre-discussion dissent. European Journal of Social Psychology, 32, 35-56. doi:10.1002/ejsp. 74

Buchs, C., Butera, F., \& Mugny, G. (2004). Resource interdependence, student interactions and performance in cooperative learning. Educational Psychology, 24, 291-314. doi:10.1080/0144341042000211661

Buchs, C., Pulfrey, C., Gabarrot, F., \& Butera, F. (2010). Competitive conflict regulation and informational dependence in peer learning. European Journal of Social Psychology, 40, 418-435. doi:10.1002/ejsp.631

Butera, F., Caverni, J.-P., \& Rossi, S. (2005). Interaction with a high- versus low-competence influence source in inductive reasoning. Journal of Social Psychology, 145, 173-190. doi:10.3200/SOCP.145.2.173-190

Butera, F., \& Mugny, G. (1995). Conflict between incompetences and influence of a lowcompetence source in hypothesis testing. European Journal of Social Psychology, 25, 457-462. doi:10.1002/ejsp.2420250408

Butera, F., \& Mugny, G. (2001). Conflicts and social influences in hypothesis testing. In C. De Dreu \& N. De Vries (Eds.), Group consensus and minority influence: Implications for innovation (pp. 160-182). Oxford: Blackwell.

Butera, F., Mugny, G., Legrenzi, P., \& Pérez, J.A. (1996). Majority and minority influence, task representation and inductive reasoning. British Journal of Social Psychology, 35, 123-136.

Darnon, C., Butera, F., \& Harackiewicz, J. (2007). Achievement goals in social interactions: Learning within a mastery vs. performance goal. Motivation and Emotion, 31, 61-70. doi:10.1007/s11031-006-9049-2

Darnon, C., Harackiewicz, J., Butera, F., Mugny, G., \& Quiamzade, A. (2007). Performanceapproach and performance-avoidance goals: When uncertainty makes a difference. Personality and Social Psychology Bulletin, 33, 813-827. doi:10.1177/0146167207301022

Darnon, C., Muller, D., Schrager, S., Pannuzzo, N., \& Butera, F. (2006). Mastery and performance goals predict epistemic and relational conflict regulation. Journal of Educational Psychology, 98, 766-776. doi:10.1037/0022-0663.98.4.766

De Dreu, C. K. W., \& Carnevale, P. J. D. (2003). Motivational bases for information processing and strategic choice in conflict and negotiation. In M.P. Zanna (Ed.), Advances in experimental social psychology (Vol. 35, pp. 235-291). New York: Academic Press.

De Dreu, C. K. W., Nijstad, B. A., \& van Knippenberg, D. (2008). Motivated information processing in group judgment and decision making. Personality and Social Psychology Review, 12, 22-49. doi:10.1177/1088868307304092

De Dreu, C. K. W., \& Van Knippenberg, D. (2005). The possessive self as a barrier to constructive conflict management: Effects of mere ownership, process accountability, and self-concept clarity on competitive cognitions and behavior. Journal of Personality and Social Psychology, 89, 345-357. doi:10.1037/0022-3514.89.3.345

De Dreu, C. K. W., Weingart, L. R., \& Kwon, S. (2000). Influence of social motives on integrative negotiation: A meta-analytical review and test of two theories. Journal of Personality and Social Psychology, 78, 889-905. doi:10.1037/0022-3514.78.5.889

Deutsch, M. (1949). A theory of cooperation and competition. Human Relations, 2, 199-231.

Deutsch, M. (1973). The resolution of conflict: Constructive and destructive processes. New Haven: Yale University Press.

Frey, D. (1986). Recent research on selective exposure to information. In L. Berkowitz (Ed.), Advances in experimental social psychology (Vol. 19, pp. 41-80). New York: Academic Press.

Frey, D., \& Schulz-Hardt, S. (2001). Confirmation bias in group information seeking and its implications for decision making in administration, business and politics. In F. Butera \& G. 
Mugny (Eds.), Social influence in social reality (pp. 53-74). Göttingen: Hogrefe \& Huber Publishers.

Gigone, D., \& Hastie, R. (1993). The common knowledge effect: Information sharing and group judgment. Journal of Personality and Social Psychology, 65, 959-974. doi:10.1037/00223514.65.5.959

Gigone, D., \& Hastie, R. (1997). The impact of information on small group choice. Journal of Personality and Social Psychology, 72, 132-140. doi:10.1037/0022-3514.72.1.132

Greitemeyer, T. \& Schulz-Hardt, S. (2003). Preference-consistent evaluation of information in the hidden profile paradigm: Beyond group-level explanations for the dominance of shared information in group decisions. Journal of Personality and Social Psychology, 84, 322-339. doi:10.1037/0022-3514.84.2.322

Homan, A. C., Hollenbeck, J. R., Humphrey, S. E., Van Knippenberg, D., Ilgen, D. R., \& Van Kleef, G. A. (2008). Facing differences with an open mind: Openness to experience, salience of intragroup differences, and performance of diverse groups. Academy of Management Journal, $58,1204-1222$.

Hornsey, M. J., \& Jetten, J. (2004). The individual within the group: Balancing the need to belong with the need to be different. Personality and Social Psychology Review, 8, 248-264. doi:: 10.1207/s15327957pspr0803_2

Janis, I. L. (1972). Victims of groupthink: A psychological study of foreign policy decisions and fiascoes. Boston: Houghton Mifflin Company.

Jetten, J., Hornsey, M. J., \& Adarves-Yorno, I. (2006). When group members admit to being conformist: The role of relative intragroup status in conformity self-reports. Personality and Social Psychology Bulletin, 32, 162-173. doi:: 10.1177/0146167205279904

Johnson, D. W., \& Johnson, R. (1989). Cooperation and competition: Theory and research. Edina, MN: Interaction Book Company.

Johnson, D. W, \& Johnson, R. T. (2005). New developments in social interdependence theory. Genetic, Social and General Psychology Monographs, 131, 285-358.

Jonas, E., Schulz-Hardt, S., Frey, D., \& Thelen, N. (2001). Confirmation bias in sequential information search after preliminary decisions: An expansion of dissonance theoretical research on selective exposure to information. Journal of Personality and Social Psychology, 80, 557-571. doi:: 10.1037/0022-3514.80.4.557

Lam, S. S. K., \& Schaubroeck, J. (2000). The effects of group decision support systems on pooling of unshared information during group discussion. Journal of Applied Psychology, 85, 565-573. doi:10.1037/0021-9010.85.4.565

Legrenzi, P., Butera, F., Mugny, G., \& Pérez, J. A. (1991). Majority and minority influence in inductive reasoning: A preliminary study. European Journal of Social Psychology, 21, 359-363. doi:10.1002/ejsp.2420210408

Lemaine, G., \& Personnaz, B. (1981). Dissimilation, differential information and social identity. European Journal of Social Psychology, 11, 27-42. doi:10.1002/ejsp.2420110102

Leyens, J.-Ph, Dardenne, B., Yzerbyt, V., Scaillet, N. \& Snyder, M. (1999). Confirmation and disconfirmation: Their social advantages. In W. Stroebe \& M. Hewstone (Eds.), European review of social psychology (Vol. 10, pp. 199-230). Chichester: Wiley.

Mojzisch, A., \& Schulz-Hardt, S. (2010). Knowing others' preferences degrades the quality of group decisions. Journal of Personality and Social Psychology, 98, 794-808. doi:10.1037/a0017627

Muller, D., Judd, C. M., \& Yzerbyt, V. Y. (2005). When moderation is meditated and when mediation is moderated. Journal of Personality and Social Psychology, 89, 852-863. doi:10.1037/00223514.89.6.852

Murnighan, J. K., Babcock, L., Thompson, L., \& Pillutla, M. M. (1999). The information dilemma in negotiations: Effects of experience, incentives, and integrative potential. International Journal of Conflict Management, 10, 313-339. doi:10.1108/eb022828

Nemeth, C. J. (1986). The differential contributions of majority and minority influence. Psychological Review, 93, 23-32. doi:10.1037/0033-295X.93.1.23 
Nemeth, C. \& Rogers, J. (1996). Dissent and the search for information. British Journal of Social Psychology, 35, 67-76.

Ross, M., \& Wilson, A. E. (2003). Autobiographical memory and conceptions of self: Getting better all the time. Current Directions in Psychological Science, 12, 66-69. doi:10.1111/14678721.01228

Schulz-Hardt, S., Brodbeck, F. C., Mojzisch, A., Kerschreiter, R., \& Frey, D. (2006). Group decision making in hidden profile situations: Dissent as a facilitator for decision quality. Journal of Personality and Social Psychology, 91, 1080-1093. doi:10.1037/0022-3514.91.6.1080

Schulz-Hardt, S., Frey, D., Luthgens, C., \& Moscovici, S. (2000). Biased information search in group decision making. Journal of Personality and Social Psychology, 78, 655-669. doi:10.1037/0022-3514.78.4.655

Schulz-Hardt, S., Jochims, M., \& Frey, D. (2002). Productive conflict in group decision making: Genuine and contrived dissent as strategies to counteract biased information seeking. Organizational Behavior and Human Decision Processes, 88, 563-586. doi:10.1016/S07495978(02)00001-8

Sessa, V. I., Jackson, S. E., \& Rapini, D. T. (1995). Workforce diversity: The good, the bad, and the reality. In G. R. Ferris, S. D. Rosen, \& D. T. Barnum (Eds.), Handbook of buman resources management. Cambridge, MA: Blackwell Publishers.

Steinel, W., \& De Dreu, C. K. W. (2004). Social motives and strategic misrepresentation in social decision making. Journal of Personality and Social Psychology, 86, 419-434. doi:10.1037/0022-3514.86.3.419

Tjosvold, D., Johnson, D. W., \& Lerner, J. (1981). Effects of affirmation of one's competence, personal acceptance, and disconfirmation of one's competence on incorporation of opposing information on problem-solving situations. Journal of Social Psychology, 114, 103-110.

Toma, C., \& Butera, F. (2009). Hidden profiles and concealed information: Strategic information sharing and use in group decision making. Personality and Social Psychology Bulletin, 35 , 793-806. doi:10.1177/0146167209333176

Winquist, J. R., \& Larson, J. R., Jr. (1998). Information pooling: When it impacts group decision making. Journal of Personality and Social Psychology, 74, 371-377. doi:10.1037/00223514.74.2.371

Wittenbaum, G. M., Hollingshead, A. B., \& Botero, I. C. (2004). From cooperative to motivated information sharing in groups: Moving beyond the hidden profile paradigm. Communication Monographs, 71, 286-310. doi:10.1080/0363452042000299894

Wittenbaum, G. M., \& Stasser, G. (1996). Management of information in small groups. In A. M. Brower \& J. L. Nye (Eds.), What's social about social cognition? Research on socially shared cognition in small groups (pp. 3-28). Thousand Oaks, CA: Sage Publications.

Received I2 April 2010; revised version received I3 April 201 I 